\title{
Analysis of Knowledge, Beliefs, and Attitudes of Patients in the Emergency Service Toward Rational Drug Use
}

\author{
(D) Șeyda Can \\ Department of Medical Nursing, Faculty of Health Sciences, Yalova University, Yalova, Turkey
}

\section{Abstract}

BACKGROUND/AIMS: Irrational drug use results in the inability to get the expected outcome from the treatment and inappropriate demands of patients stemming from overuse of drugs and drug addiction, and these factors lead to an increased number of applications to health institutions. This study aimed to identify the factors that affect the knowledge, beliefs, and attitudes of patients presenting to the emergency department in terms of rational drug use.

MATERIALS and METHODS: This is descriptive cross-sectional research that includes patients who applied for treatment to the emergency department of a state hospital in Turkey between 01.08.2019-31.12.2019. The study sample was composed of 262 patients who agreed to participate in the study. The study used the Rational Drug Use Scale (RDUS) and Drug Use Health Belief Scale (DUHBS) as data collection tools.

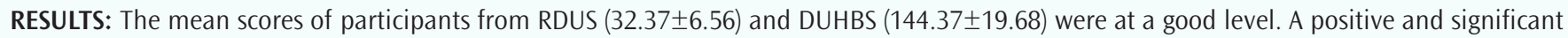
relationship was found between RDUS and DUHBS mean score of patients $(p<0.01)$. Knowledge of rational drug use differed according to age, gender, economic status, educational level, and reasons for applying to the emergency department variables $(p<0.05)$, and health beliefs regarding drug use varied according to the gender variable $(p<0.01)$.

CONCLUSION: Study results are significant since they revealed the factors that affect the patients' knowledge of rational drug use and their related health beliefs, as well as the relationship between these factors.

Keywords: Attitude; emergency department; health belief model; knowledge; rational drug use

\section{INTRODUCTION}

Emergency departments are special units where health services are provided every hour daily, and many patients with urgency are quickly evaluated and given medical services. ${ }^{1}$ However, inappropriate use of the emergency department leads to an excessive number of patients and consequent serious problems in health service delivery. ${ }^{2}$ Moreover, patients' improper emergency applications result in excessive examination and treatment use. ${ }^{3}$ The use of emergency departments by patients without urgency is a universal health problem, and many reasons arise that emergency departments are preferred instead of primary healthcare services. ${ }^{4,5}$ Health and disease-related behaviors are affected by a variety of factors, such as the habits of the society in which the individual lives, knowledge and health literacy level, health inequalities, mental capacity and social media. ${ }^{6}$ Rational drug use, which has a great impact on outcomes, such as compliance with treatment and health costs, is an important aspect of the health management system.,8 Today, irrational drug use leads to inappropriate use of resources, thereby reducing drug access and causing many health, economic, social, and political problems. ${ }^{9}$ Rational drug use ensures that individuals can easily obtain the suitable drug according to their clinical symptoms and individual characteristics in a suitable time and dosage at the most reasonable cost. However, many

To cite this article: Can \$̧. Analysis of Knowledge, Beliefs, and Attitudes of Patients in the Emergency Service Toward Rational Drug Use. Cyprus J Med Sci 2021;6(Suppl 1):35-42

ORCID iDs of the authors: S.C. 0000-0001-9733-133X 
countries experience problems that are related to the overusage of drugs. ${ }^{10}$

Rational behavior is affected by correct and sufficient knowledge, as well as beliefs and attitudes. Health Belief Model (HBM) explains the attitudes and beliefs that affect and facilitate individuals' behaviors in their health and disease status. ${ }^{11}$ According to the HBM, for the individual to acquire positive health behavior or quit negative health behavior, first of all, identifying the beliefs and attitudes that prevent the individual and the group from adopting that behavior is necessary. ${ }^{12}$

Irrational drug use results in negative outcomes, such as not receiving any benefits from the treatment, inappropriate patient demands caused by drug overusage, and drug addiction, and these factors cause several applications to health institutions to increase. Identifying the patients' knowledge and behaviors regarding rational drug uses, which is a multi-factor process, will guide the improvements in this field in the future. ${ }^{13}$ This study aimed to identify the factors that affect rational drug use behavior by examining the knowledge, beliefs, and attitudes of patients who present to the emergency department of a state hospital in rational drug use. Thus, in line with the obtained findings, it was aimed to inform the patients and raise their awareness about rational drug use.

\section{MATERIALS and METHOD}

\section{Study Design and Setting}

The study has a descriptive and cross-sectional design, which aimed to analyze the knowledge, beliefs, and attitudes of the patients presenting to the emergency department regarding rational drug use.

\section{Study Sample}

The study population consisted of patients who applied for treatment to the emergency department of a state hospital in Turkey between 01.08.2019-31.12.2019. The study sample was composed of 262 who applied to the emergency department of the relevant hospital.

\section{Sample Selection Criteria:}

- 18 years of old and above

- literate

- voluntary participation

- received examination and healthcare services

This study aimed to address the following questions:

Q1: What are the demographic characteristics of patients who present to the emergency department?
Q2: What is the knowledge level of patients who present to the emergency department regarding rational drug use?

Q3: What are the health beliefs of patients who present to the emergency department regarding rational drug use?

Q4: What is the relationship between the demographic characteristics of patients who present to the emergency department and their knowledge level and health beliefs regarding rational drug use?

Q5: What is the relationship between the knowledge level of patients present to the emergency department regarding rational drug use and their health beliefs?

\section{Data Collection}

Data were collected from individuals who voluntarily participated in the research in the waiting room of the emergency service. Data collection periods were the available and preferred time of patients while waiting for the test results or after all their procedures in the emergency service ended. The data were collected in 15 min on average through the face-toface interview method.

\section{Data Collection Tools}

In the collection of the data, "Identifying Information Form", "Rational Drug Use Scale" and "Drug Use Health Belief Scale" was employed.

\section{Identifying Information Form}

The identifying Information Form used in the data collection was developed by the researcher who reviewed the literature. ${ }^{14,15}$ The form, which investigates the identifying information about the patients, includes 8 questions that determine demographic characteristics (age, gender, and marital status), socioeconomic characteristics (economic status and educational level), and information about diseases (chronic disease, drug use, and the reason for the emergency department visit).

\section{Rational Drug Use Scale (RDUS)}

The validity and reliability study of the RDUS, which assesses the knowledge level of rational drug use, was performed by Demirtaș et al. ${ }^{14}$ in 2018. The scale consists of a total of 21 statements, of which 10 are correct and 11 are incorrect. Each statement is assessed with three options as "correct," "incorrect," and "don't know." The "correct" answer gets a score of 2, "do not know" as 1, and "incorrect" as 0 . As the level of knowledge increases, the score obtained from the scale also increases. The scale, which is used in Turkey to determine the knowledge level regarding rational drug use, is a scale whose validity and reliability studies have been completed. The validity and reliability study conducted by Demirtaș et al. ${ }^{14}$ revealed that Cronbach's alpha coefficient of the scale was 0.789 . The present study revealed Cronbach's alpha 
coefficient as 0.804 . The obtained result revealed the reliability of the scale.

\section{Drug Use Health Belief Scale (DUHBS)}

The DUHBS structured following the HBM was developed by Çiçek ${ }^{16}(2012)$ to evaluate the health belief perceptions regarding drug use. Consisting of 36 items, the scale has six subdimensions, which include Perceived Susceptibility, Perceived Severity, Health Motivation, Perceived Benefit, Perceived Barriers, and Self-Efficacy. Perceived Susceptibility (items 1 to 6) determines the risks perceived by individuals related to unconscious and unprescribed drug use. Perceived Severity (items 7 to 12) indicates how seriously harmful the outcomes that occur due to unconscious drug use are perceived in terms of physical health. Health Motivation (items 13 to 18) identifies internal/external resources and willingness that determine responsible drug use behavior. Perceived Benefit (items 19 to 22) demonstrates perceived benefits due to conscious drug use. Perceived Barriers (Items 23 to 28) determine the barriers perceived by individuals in conscious drug use. These items are considered negative, and scores are reversely calculated. High scores obtained from the subdimension of Perceived Barriers suggest that the individual evaluates the barriers related to rational drug use as reasonable. Self-Efficacy (items 29 to 36) encompasses the individual's selfbelief, determination, and will in the realization of conscious drug use behavior. ${ }^{15}$

Each item is scored as $1-5$ and is evaluated on a 5-Point Likerttype scale. The item scoring is as follows: Strongly disagree as 1 , Disagree as 2, Neither Agree Nor Disagree as 3, Agree as 4, and Strongly Agree as 5 points. A higher score obtained on the scale indicates a higher level of health belief in terms of conscious and prescribed drug use. Cronbach's alpha coefficient of the scale developed by Erci and Çiçek ${ }^{15}$ (2017) was 0.910 . The Cronbach's alpha of the scale in the present study was 0.916. This result showed the reliability of the scale.

\section{Ethical Considerations}

Ethics Board of the hospital approval (decision no: 2019-9/9) and hospital permission were obtained for the study. Permission was also taken from the authors of the scale used in the study. Care was taken to observe ethical principles at all stages of the study.

\section{Statistical Analysis}

Data were analyzed through Statistical Package for the Social Sciences version 24.0 (SPSS Inc., Chicago, IL, USA) package program. The study calculated the scale scores, and The Skewness and Kurtosis coefficients were examined to determine the normally distributed scores. As the scores displayed normal distribution, parametric test techniques were used. T-test and analysis of variance (ANOVA) were used to analyze whether the scale score varied according to demographic characteristics. The t-test was used for the analysis of 2-group demographic variables, whereas ANOVA was employed for the analysis of variables with the $k(k>2)$ group. Additionally, the relationship between the scale scores was analyzed with the Pearson correlation test.

\section{RESULTS}

\section{Distribution of the Demographic Characteristic of Patients Who Presented to the Emergency Department}

The evaluation of the distribution of participants according to demographic characteristics revealed that $32.8 \%(n=86)$ were between the ages of 13 and 31 years, $79.4 \%(n=208)$ were females, and $67.2 \%(n=176)$ were married. Of the patients, $35.9 \%$ $(n=94)$ had primary school education, whereas $71 \%(n=186)$ had medium level of economic status. While $61.1 \%(n=160)$ of patients presented to the emergency department had no chronic diseases, $42.7 \%$ ( $n=112)$ were determined to use drugs regularly. The evaluation of the reasons for patients to present to the emergency department revealed that the highest percentage was related with pain due to digestive or urological problems with $40.5 \%$ ( $n=106)$, followed by respiratory system with $20.6 \%(n=54)$, and cardiovascular complaints with $13 \%(n=34)$, respectively (Table 1).

\section{Findings Related to the Distribution of RDUS and DUHBS Item Mean Scores of Patients Who Presented to the Emergency Department}

RDUS total mean score of patients who presented to the emergency department was 32.37 \pm 6.56 (Table 2).

DUHBS total mean score was $144.37 \pm 19.68$. The evaluation of the subdimensions of the HBM revealed that the Self-Efficacy mean score was $29.79 \pm 5.27$, Health Motivation was $25.45 \pm 4.91$, Perceived Susceptibility was $25.10 \pm 5.10$, Perceived Severity was $24.77 \pm 4.71$, Perceived Barriers was $21.95 \pm 7.35$, and Perceived Benefit was 17.29 \pm 3.04 (Table 2). Item mean scores of the scale subdimensions from the highest to the lowest were found as Perceived Benefit (4.32 \pm 0.76$)$, Self-Efficacy (4.26 \pm 0.74$)$, Health Motivation (4.24 \pm 0.81$)$, Perceived Susceptibility (4.18 \pm 0.85$)$, Perceived Severity (4.12 \pm 0.78$)$, and Perceived Barriers (3.65 \pm 1.22$)$, respectively (Table 2 ).

\section{The Relationship Between the Individual Characteristics of Patients Who Presented to the Emergency Department and RDUS and DUHBS Total Mean Scores}

Study results revealed no statistically significant difference between RDUS total mean scores and marital status, presence of chronic diseases, and drug use status of patients who presented to the emergency department $(p>0.05)$. Contrarily, a statistically significant relationship was determined between RDUS total mean scores and the patients' age, gender, economic status, and reasons for presenting to the emergency department $(p<0.05)$ (Table 3). 


\begin{tabular}{|c|c|c|}
\hline Characteristics & Min-Max & Mean \pm SD (median) \\
\hline \multirow[t]{2}{*}{ Age (years) } & $18-79$ & $42.13 \pm 16.75$ \\
\hline & $\mathrm{n}$ & $\%$ \\
\hline \multicolumn{3}{|l|}{ Age groups } \\
\hline $18-31$ & 86 & 32.8 \\
\hline $32-45$ & 66 & 25.2 \\
\hline $46-59$ & 62 & 23.7 \\
\hline $60-79$ & 48 & 18.3 \\
\hline \multicolumn{3}{|l|}{ Gender } \\
\hline Female & 208 & 79.4 \\
\hline Male & 54 & 20.6 \\
\hline \multicolumn{3}{|l|}{ Marital status } \\
\hline Married & 176 & 67.2 \\
\hline Single & 86 & 32.8 \\
\hline \multicolumn{3}{|l|}{ Economic status } \\
\hline Good & 50 & 19.1 \\
\hline Medium & 186 & 71.0 \\
\hline Poor & 26 & 9.9 \\
\hline
\end{tabular}

Educational level

\begin{tabular}{|l|l|l|}
\hline Literate & 24 & 9.2 \\
Primary school & 94 & 35.9 \\
High school & 92 & 35.1 \\
University and above & 52 & 19.8 \\
\hline Chronic disease & 102 & 38.9 \\
\hline Yes & 160 & 61.1 \\
No & \multicolumn{2}{|l|}{} \\
\hline Regular drug use & \multicolumn{2}{|l|}{} \\
\hline Yes & 112 & 42.7 \\
No & 150 & 57.3 \\
\hline
\end{tabular}

Reasons for presenting to the emergency department

\begin{tabular}{|c|c|c|}
\hline 1. Pain (GIS or urology) & 106 & 40.5 \\
\hline 2. Respiration & 54 & 20.6 \\
\hline 3. Cardiovascular & 34 & 13.0 \\
\hline 4. Psychiatric & 26 & 9.9 \\
\hline 5. Trauma & 16 & 6.1 \\
\hline 6. Allergy & 12 & 4.6 \\
\hline 7. Other* & 14 & 5.3 \\
\hline Total & 262 & \\
\hline
\end{tabular}

Table 2. Distribution of RDUS and DUHBS item mean scores of the patients who presented to the emergency department $(n=262)$

\begin{tabular}{|c|c|c|c|c|c|}
\hline $\begin{array}{l}\text { Scale and } \\
\text { subdimensions }\end{array}$ & Min & Max & Mean & SD & \\
\hline RDUS (total score) & 15.00 & 42.00 & 32.37 & 6.56 & \\
\hline $\begin{array}{l}\text { Scale and } \\
\text { subdimensions }\end{array}$ & Min & Max & Mean & SD & $\begin{array}{l}\text { Item } \\
\text { Mean } \\
\text { Score }\end{array}$ \\
\hline DUHBS (total score) & 74.00 & 175.00 & 144.37 & 19.68 & \\
\hline $\begin{array}{l}\text { Perceived } \\
\text { susceptibility }\end{array}$ & 6.00 & 30.00 & 25.10 & 5.10 & $4.18 \pm 0.85$ \\
\hline Perceived severity & 11.00 & 30.00 & 24.77 & 4.71 & $4.12 \pm 0.78$ \\
\hline Health motivation & 6.00 & 30.00 & 25.45 & 4.91 & $4.24 \pm 0.81$ \\
\hline Perceived benefit & 4.00 & 20.00 & 17.29 & 3.04 & $4.32 \pm 0.76$ \\
\hline Perceived barriers & 6.00 & 30.00 & 21.95 & 7.35 & $3.65 \pm 1.22$ \\
\hline Self-efficacy & 11.00 & 35.00 & 29.79 & 5.27 & $4.26 \pm 0.74$ \\
\hline
\end{tabular}

No statistically significant difference was found between DUHBS total mean scores and the patients' age, marital status, educational level, presence of chronic disease, drug use, and reasons for presenting to the emergency department $(p>0.05)$. A statistically significant relationship was identified between the patients' gender and DUHBS total mean scores $(p<0.01)$. Health belief perceptions of females regarding drug use were found to be higher than those of males (Table 3).

\section{The Relationship Between the Patients' RDUS Total Mean Scores and DUHBS Subdimensions Total Item Mean Scores}

Study results revealed a positive and significant relationship between the patients' RDUS total mean scores and DUHBS total and Perceived Susceptibility, Health Motivation, and Perceived Barriers subdimensions item mean scores $(p<0.01)$ (Table 4$)$.

No significant relationship was determined between RDUS total mean scores and Perceived Severity, Perceived Benefit and SelfEfficacy subdimensions item mean scores (Table 4).

\section{DISCUSSION}

The evaluation of RDUS total mean scores of patients who presented to the emergency department revealed a good patients' level of knowledge regarding rational drug use (32.37 \pm 6.56$)$. A study conducted by Aslan et al. ${ }^{17}$ (2019) revealed that RDUS mean score at a medium level (24.19 \pm 5.16$)$ Another study by Ekici et al. ${ }^{18}$ (2019) found RDUS mean score of 29.75. This difference was thought to have stemmed from the hospital where the study was conducted, the region, and the patients' characteristics. 
Table 3. Comparison of RDUS and DUHBS total mean score of the patients who presented to the emergency department $(n=262)$

\begin{tabular}{|c|c|c|c|c|c|}
\hline \multirow[b]{2}{*}{ Characteristics } & \multirow[b]{2}{*}{$\mathrm{n}$} & \multicolumn{2}{|c|}{ RDUS (total score) } & \multicolumn{2}{|c|}{ DUHBS (total score) } \\
\hline & & Mean \pm SD & $X^{2} / Z / p$ & Mean \pm SD & $X^{2} / Z / p$ \\
\hline \multicolumn{6}{|l|}{ Age groups } \\
\hline $\begin{array}{l}18-31 \\
32-45 \\
46-59 \\
60-79\end{array}$ & $\begin{array}{l}86 \\
66 \\
62 \\
48\end{array}$ & $\begin{array}{l}32.83 \pm 6.79 \\
34.33 \pm 5.18 \\
30.90 \pm 6.90 \\
30.75 \pm 6.74\end{array}$ & $\begin{array}{l}4.270 \\
0.006\end{array}$ & $\begin{array}{l}143.93 \pm 17.59 \\
142.12 \pm 20.65 \\
149.87 \pm 19.26 \\
141.16 \pm 21.52\end{array}$ & $\begin{array}{l}2.375 \\
0.071\end{array}$ \\
\hline \multicolumn{6}{|l|}{ Gender } \\
\hline $\begin{array}{l}\text { Female } \\
\text { Male }\end{array}$ & $\begin{array}{l}208 \\
54\end{array}$ & $\begin{array}{l}32.86 \pm 6.27 \\
30.48 \pm 7.36\end{array}$ & $\begin{array}{l}2.398 \\
0.017\end{array}$ & $\begin{array}{l}146.31 \pm 17.98 \\
136.88 \pm 23.95\end{array}$ & $\begin{array}{l}3.190 \\
0.002\end{array}$ \\
\hline \multicolumn{6}{|l|}{ Marital status } \\
\hline $\begin{array}{l}\text { Married } \\
\text { Single }\end{array}$ & $\begin{array}{l}176 \\
86\end{array}$ & $\begin{array}{l}31.82 \pm 6.53 \\
33.48 \pm 6.53\end{array}$ & $\begin{array}{l}-1.930 \\
0.055\end{array}$ & $\begin{array}{l}144.38 \pm 20.27 \\
144.34 \pm 18.54\end{array}$ & $\begin{array}{l}0.014 \\
0.988\end{array}$ \\
\hline \multicolumn{6}{|l|}{ Economic status } \\
\hline $\begin{array}{l}\text { Good } \\
\text { Medium } \\
\text { Poor }\end{array}$ & $\begin{array}{l}50 \\
186 \\
26\end{array}$ & $\begin{array}{l}34.32 \pm 5.73 \\
31.68 \pm 6.88 \\
33.53 \pm 4.79\end{array}$ & $\begin{array}{l}3.693 \\
0.026\end{array}$ & $\begin{array}{l}141.04 \pm 21.66 \\
145.11 \pm 18.80 \\
145.46 \pm 21.98\end{array}$ & $\begin{array}{l}0.889 \\
0.412\end{array}$ \\
\hline \multicolumn{6}{|l|}{ Educational level } \\
\hline $\begin{array}{l}\text { Literate } \\
\text { Primary School } \\
\text { High School } \\
\text { University }\end{array}$ & $\begin{array}{l}24 \\
94 \\
92 \\
52\end{array}$ & $\begin{array}{l}32.75 \pm 6.97 \\
32.14 \pm 4.60 \\
30.93 \pm 7.35 \\
35.15 \pm 7.19\end{array}$ & $\begin{array}{l}4.846 \\
0.003\end{array}$ & $\begin{array}{l}144.25 \pm 18.47 \\
146.61 \pm 20.00 \\
144.39 \pm 20.55 \\
140.34 \pm 17.88\end{array}$ & $\begin{array}{l}1.134 \\
0.336\end{array}$ \\
\hline \multicolumn{6}{|l|}{ Chronic disease } \\
\hline $\begin{array}{l}\text { Yes } \\
\text { No }\end{array}$ & $\begin{array}{l}102 \\
160\end{array}$ & $\begin{array}{l}31.84 \pm 5.56 \\
32.71 \pm 7.12\end{array}$ & $\begin{array}{l}-1.045 \\
0.297\end{array}$ & $\begin{array}{l}144.47 \pm 21.70 \\
144.31 \pm 18.36\end{array}$ & $\begin{array}{l}0.063 \\
0.950\end{array}$ \\
\hline \multicolumn{6}{|l|}{ Regular drug use } \\
\hline $\begin{array}{l}\text { Yes } \\
\text { No }\end{array}$ & 112150 & $\begin{array}{l}31.75 \pm 6.02 \\
32.84 \pm 6.92\end{array}$ & $\begin{array}{l}-1.331 \\
0.184\end{array}$ & $\begin{array}{l}146.76 \pm 21.11 \\
142.58 \pm 18.42\end{array}$ & $\begin{array}{l}1.707 \\
0.089\end{array}$ \\
\hline \multicolumn{6}{|l|}{ Reason for presenting } \\
\hline $\begin{array}{l}\text { 1.Pain (GIS/Urology) } \\
\text { 2.Respiration } \\
\text { 3.Cardiovascular } \\
\text { 4.Psychiatric } \\
\text { 5.Trauma } \\
\text { 6.Allergy } \\
\text { 7.Other }\end{array}$ & $\begin{array}{l}106 \\
54 \\
34 \\
26 \\
16 \\
12 \\
14\end{array}$ & $\begin{array}{l}32.20 \pm 5.94 \\
30.96 \pm 7.31 \\
33.00 \pm 5.54 \\
30.61 \pm 7.61 \\
34.50 \pm 8.26 \\
36.16 \pm 3.15 \\
35.14 \pm 6.43\end{array}$ & $\begin{array}{l}2.210 \\
0.043\end{array}$ & $\begin{array}{l}146.60 \pm 17.81 \\
139.88 \pm 20.98 \\
140.52 \pm 16.48 \\
146.69 \pm 30.75 \\
146.75 \pm 17.01 \\
140.50 \pm 16.84 \\
150.42 \pm 10.34\end{array}$ & $\begin{array}{l}1.316 \\
0.250\end{array}$ \\
\hline
\end{tabular}

Our study results revealed a significant relationship between age, gender, economic status, educational level, and reasons for presenting to the emergency department, and rational drug use knowledge $(p<0.05)$ (Table 3). Patients with the highest level of rational drug use knowledge in terms of age variable were participants between the ages of 32 and 45 years, whereas the lowest was in the 60-79 age group. As one gets older, his/ her access to knowledge and understanding and utilizing knowledge decreases. ${ }^{19}$ Therefore, rational drug use knowledge mean scores significantly differed in terms of age. The study revealed that the female participants' mean score related to rational drug use knowledge (32.86 \pm 6.27$)$ was higher compared to males. Contrarily, other studies revealed no significant difference between the gender variable and rational drug use 


\begin{tabular}{|c|c|c|}
\hline \multirow{2}{*}{ Variable } & \multicolumn{2}{|c|}{ RDUS (total score) } \\
\hline & $r$ & $p$-value \\
\hline DUHBS (total score) & $0.249 * *$ & 0.000 \\
\hline Perceived susceptibility & $0.260 * *$ & 0.000 \\
\hline Perceived severity & -0.119 & 0.055 \\
\hline Health motivation & $0.262 * *$ & 0.000 \\
\hline Perceived benefit & -0.004 & 0.950 \\
\hline Perceived barriers & $0.386^{* *}$ & 0.000 \\
\hline Self-efficacy & 0.004 & 0.954 \\
\hline \multicolumn{3}{|c|}{$\begin{array}{l}* * p<0.01 \text { RDUS, Rational Drug Use Scale; DUHBS, Drug Use Health Belief Scale } \\
\text { Significant values are shown in bold. }\end{array}$} \\
\hline \multicolumn{3}{|c|}{ RDUS, Rational Drug Use Scale; DUHBS, Drug Use Health Belief Scale. } \\
\hline
\end{tabular}

knowledge. ${ }^{11-17}$ Pirinçci and Bozan ${ }^{20}$ determined in their study that rational drug use behaviors of male nurses developed more than female nurses, contrary to our study results. Likewise, a study conducted by Kaya et al..$^{21}$ revealed that rational drug use behavior of male students developed more than female students. A study conducted by Beggi and Așı $\mathrm{K}^{22}$ (2019) revealed that women were using their prescribed drugs more regularly, in parallel with our study findings. This difference in research results was thought to be caused by the difference in other demographic characteristics of male and female participants (age, educational level, profession, etc.). The evaluation of rational drug use knowledge according to economic status revealed that RDUS mean scores of participants in good economic condition statistically significantly differed. Therefore, as individual's income increases, their access to health-related knowledge will be easier and they will use this knowledge more easily. However, the study conducted by Aslan et al. ${ }^{17}$ revealed no significant difference between the participants' economic status and their knowledge of rational drug use. The evaluation of the participants' knowledge levels of rational drug use concerning their educational level revealed that as their educational levels increased, their RDUS mean scores also increased. The study revealed that use of drugs knowledge of participants with a university degree was higher (35.15 \pm 7.19$)$. The study conducted by Aslan et al. ${ }^{23}$ revealed no significant difference between the participants' educational levels and their knowledge of rational drug use. Macit et al..$^{23}$ found a significant difference between educational levels and knowledge of rational drug use in their study in individuals' knowledge level of rational drug use. As individuals' educational levels increased, they could easily access health information and understand and make use of this information, thereby having higher levels of knowledge related to rational drug use. Within the scope of the study, participants' reasons for presenting to the emergency department were also evaluated, which revealed a significant relationship between their reasons for applying to the emergency department and their knowledge level of rational drug use $(p<0.05)$. Additionally, RDUS mean scores (36.16 \pm 3.15$)$ of patients who presented to the emergency department for allergic problems were higher. Macit et al..$^{23}$ (2019) reported that participants with food or drug allergy informed the doctor or health professional about their condition during the examination at quite high rates. Allergic complaints have a determining effect on the personal attitude and behavior of the patient toward his/her health/disorder in the long term. The high awareness levels of patients with an allergic history are suggested to affect their knowledge levels of rational drug use.

The DUHBS total mean score of the study participants was 144.37 \pm 19.68 . DUHBS identifies individual perceptions, which are believed to affect the use of drugs. The study revealed that participants have a high level of health belief regarding rational drug use when the maximum obtained score was considered. The total mean score of health belief regarding drug use obtained in the study shows similarity to other conducted studies. ${ }^{24,25}$ The evaluation of the subdimensions of DUHBS revealed that while the subdimensions of Perceived Benefit $(4.32 \pm 0.76)$ and SelfEfficacy (4.26 \pm 0.74$)$ had the highest item mean scores, Perceived Barriers (3.65 \pm 1.22$)$ subdimension had the lowest item mean score. Perceived Benefit subdimension refers to the individuals' perception of the outcomes and benefits of conscious drug use. Individuals with a high level of Perceived Benefit know that conscious and prescribed drug use provides recovery, prevents complications, and protects his/her legal rights. Contrarily, SelfEfficacy is one of the effective factors on how an individual will think how s/he will behave and be motivated for taking action. Individuals with a high level of Self-Efficacy have high self-confidence and competence in realizing conscious drug use behavior. ${ }^{16}$ Teke and Arslan ${ }^{25}$ found high levels of Self-Efficacy in their study to determine the levels of Self-Efficacy and compliance with pharmaceutical treatment in individuals with hypertension. Similar to our study, Özer ${ }^{24}$ determined that the Perceived Benefit and Self-Efficacy mean score in patients with chronic diseases was high, whereas the Perceived Barriers level was low.

Our study results revealed that the patients' perceptions of health belief regarding drug use (DUHBS) did not statistically significantly different in terms of their age, marital status, economic status, educational level, presence of chronic disease, drug use, and reasons for presenting to the emergency department $(p>0.05)$. However, a significant relationship was identified between the patients' gender and their DUHBS mean scores $(p<0.01)$. This result indicates that females had higher levels of health beliefs regarding drug use compared to those of males (Table 3). Therefore, beliefs, such as susceptibility, benefit, severity, and motivation, were more effective on the behavior of females regarding rational drug use than on males. A meta-analysis conducted by Abegaz and friends revealed that drug conformity of males was lower than that of females but 
was not statistically significant. ${ }^{26}$ Studies showed that the belief and conformity of females to the treatment are better than that of males. ${ }^{27}$ A study conducted by Kahraman et al. ${ }^{28}$ revealed no significant difference between the variables of gender and marital status and the attitude and belief development toward obesity. The study conducted by Nișancı Kılınç et al. ${ }^{11}$ revealed that the patients' health beliefs significantly differed in terms of age variable, but no significant difference in terms of gender, educational level, and employment status. Gender significantly determines attitudes, behaviors, preferences, and tendencies. This situation significantly affects both the mental and physical attitude of females and males, as well as their perception of health/disease and their way of being exposed to the disease. ${ }^{29}$ Our study results support these results.

No significant relationship was found between the patients' RDUS total mean score and item mean scores obtained from the subdimensions of Perceived Severity, Perceived Benefit, and SelfEfficacy in the health belief scale (Table 4). A study conducted by Nişancı Kılınç et al. ${ }^{11}$ revealed no significant difference between the individuals' educational level and health belief perception. The reasons for realized/unrealized behaviors related to health cannot be explained by a single cause. Contrary to study results, it is believed that individual variables, such as educational level, have an impact on behavior. ${ }^{30}$ A positive and significant relationship was found between the patients' RDUS and DUHBS total mean scores and Perceived Susceptibility, Health Motivation and Perceived Barriers subdimensions item mean scores $(p<0.01)$ (Table 4). The results obtained showed a positive and significant relationship between the individuals' knowledge level of rational drug use and health beliefs for drug use. HBM explains why a recommended/unrecommended health behavior was displayed, refused, or postponed by an individual. ${ }^{12}$ In the drug use health belief scale, individual perceptions, which are assumed to affect health behaviors, are revealed. The study revealed that as the knowledge level of rational drug use increased, health belief perceptions were positively affected. The knowledge level is effective on critical thinking, being responsible, and health-seeking behaviors. Therefore, as the knowledge level of rational drug use increased, susceptibility, motivation, and benefit related to the use of drugs outweighed barriers, and that Perceived Barriers increased. Perceived susceptibility, severity, benefit, and motivation reduce the effect of Perceived Barriers in the HBM, behavior develops. ${ }^{30}$ This obtained result is significant as it reveals the relationship between susceptibility, health motivation, and Perceived Barriers, which are effective in the development of health behavior and increased knowledge level of rational drug use.

\section{CONCLUSION}

Non-rational drug use increases undesired adverse effects while decreasing the expected efficiency in the treatment.
Inappropriate emergency applications of patients and excessive examination cause treatment usage and increased costs. When emergency services are not utilized according to their purpose, an excessive patient intensity was found in hospitals, and accordingly, quality is negatively affected. Therefore, the study was conducted with patients who visited the emergency service. Determining the rational drug use information, health beliefs, and affecting factors in the patient population who apply to the emergency service is important. Adopting rational drug use in increasing the quality of healthcare services, reducing costs, and especially, ensuring patient safety will also reduce inappropriate emergency applications.

This study revealed that the health beliefs of patients who presented to the emergency department in terms of rational drug use knowledge and use of drugs were at a high level. The knowledge of rational drug use differed according to age, gender, economic status, educational level, and reasons for presenting to the emergency department and their health beliefs differed according to the variable of gender. A positive relationship was found between health belief perceptions, which describe individual perceptions and are assumed to affect drug use behaviors and their knowledge of rational drug use.

Numerous factors affected health-seeking behavior. Therefore, our study results are important in terms of revealing the relationship between the knowledge of rational drugs and the factors affecting health beliefs related to drug use. Behavioral and psychological factors should be considered, beliefs should be identified, and accordingly, training and consultation should be provided to raise public awareness about rational drug use and increase public consciousness.

\section{ETHICS}

Ethics Committee Approval: Ethics Board decision (Bursa Uludağ University Faculty of Medicine Clinical Research Ethics Committee decision no. 2019-9/9) and hospital permission were obtained for the study.

Informed Consent: Written informed consent was obtained from patients who participated in this study.

Peer-review: Externally peer-reviewed.

\section{DISCLOSURES}

Financial Disclosure: The author declared that this study had received no financial support.

\section{REFERENCES}

1. Mersinlioğlu G, Öztürk H. Levels of emergency patients' satisfaction with nursing services. J Health Nurs Manag. 2015;2:70-82.

2. Şimșek P, Gürsoy A. Urgent problem of emergency departments: Inappropriate use. J Anatol Nurs Health Sci. 2015;18:312-317. 
3. Yorulmaz M, Karaalp F, Bükecik N, Özyılmaz AF. Evaluation of emergency service again application rating. J Soc Tech Res. 2017;14:92-99.

4. Hocagil AC, Bildik F, Kılıçaslan I, et al. Evaluating unscheduled readmission to emergency department in the early period. Balkan Med J. 2016;33:72-79.

5. Söyük $S$, Arslan Kurtuluş $S$. The evaluation of the problems' emergency services from staff perspectives. GÜSBD. 2017;6:44-56.

6. Demir Avcı Y. Personal health responsibility. TAF Prev Med Bull. 2016;15:259266.

7. Altındiș S. Systematic overview of rational drug use. BSHR. 2017;1:34-38.

8. Şantaş F, Demirgil B. A study on rational drug use. JOBS. 2017;5:35-48.

9. Aktaș $\mathrm{H}$, Selvi $\mathrm{H}$. Development of consciousness scale towards rational drug use in adults: Validity and reliability study. Mersin Univ J Health Sci. 2019;12:439-447.

10. Yağar F, Sosyal A. Evaluation of the hospital practices about rational drug use: Example of assistant physicians. Int J Manag Econ Bus. 2018;14:81-96.

11. Nişancı Kılınç F, Çakır B, Daşgın H, Temizhan A. Evaluation of patients with metabolic syndrome according to the health belief model scale in obesity. Med J Bakırköy. 2018;14:76-84.

12. Yılmaz Tuncay S, Demirhan I, Șahin S, Kaplan S. An example of Health Belief Model: Tobacco addiction in pregnant woman. Turk J Health Sci Res. 2019;2:38-46

13. Saygılı M, Özer Ö, Uğurluoğlu Ö. An evaluation on levels of knowledge and behavior of nurse about rational drug use in a public hospital. DEUHFED. 2015;8:162-170

14. Demirtaş Z, Dağtekin G, Sağlan R, et al. Validity and reliability of rational drug use scale. ESTUDAM Public Health J. 2018;3:37-46.

15. Erci B, Çiçek Z. Reliability and validity of drugs use Health Belief Scale in adult women. Int Arch Nurs Health Care. 2017;3:1-7.

16. Çiçek Z. The effect of training on women's unconscious use of drugs nonprescription in accordance with Health Belief Model. Atatürk University Phd Thesis, 2012

17. Aslan R, Ilıman E, Arslan A. Determination of health literacy and rational drug use levels of vocational school of health services students'. Int Soc Mental Res Think J. 2019;5:1107-1116.
18. Ekici MA, Kurutçu Ş, Uysal B. Measurement of rational drug use knowledge level in adults. J Soc Hum Sci Res. 2019;6:179-189.

19. Akbolat M, Kahraman G, Erigüç G, Sağlam H. Does patient-physician relationship affect health literacy?: A research in Sakarya province. TAF Prevent Med Bullet. 2016;15:354-362.

20. Pirinçci E, Bozan T. Rational drug use among nurses who work in a university hospital. Firat Med J. 2016;21:129-136.

21. Kaya H, Turan N, Keskin Ö, et al. Rational Drug Usage Behavior of University Students. J Anatol Nurs Health Sci. 2015;18:35-42.

22. Beggi B, Aşık Z. Evaluation of rational drug use in patients applying to family medicine outpatient clinic. Ankara Med J. 2019;19:251-260.

23. Macit M, Karaman M, Parlak M. Investigation of individuals' rational drug use knowledge levels. Istanbul Gelisim Univ J Soc Sci. 2019;6:372-387.

24. Özer E. The relationship between health beliefs and their adaptation to drug use in patients with chronic disease. Marmara University Phd Thesis 2018.

25. Teke N, Arslan S. Hypertensive individuals's medication adherence self efficacy level in rural population and determination of the affeting factors. DEUHFED. 2018;11:120-128.

26. Abegaz TM, Shehab A, Gebreyohannes EA, Bhagavathula AS, Elnour AA Nonadherence to antihypertensive drugs: A systematic review and metaanalysis. Medicine. 2017;96:E564117.

27. Dias A, Pereira C, Monteiro MJ, Santos C. Patients' beliefs about medicines and adherence to medication in ischemic heart disease. Aten Primaria. 2014:46:101-106.

28. Kahraman G, Baș T, Akbolat M. The effect of health programs on the development of attitudes and beliefs in obesity. Acibadem Univ Health Sci J. 2015;6:89-98.

29. Aytaç Ö, Kurtdaş MÇ. Social origins of ıllness-health and health sociology. Firat Univ J Soc Sci. 2015;25:231-250.

30. Bulduk S, Yurt S, Dinçer Y, Ardıç E. Health behaviour models. J Du Health Sci Inst. 2015;5:28-34. 